\title{
On the measurement of formaldehyde release from low-emission wood-based panels using the perforator method
}

\author{
E. Roffael • B. Johnsson • B. Engström
}

Received: 18 March 2010/Published online: 15 June 2010

(C) The Author(s) 2010. This article is published with open access at Springerlink.com

\begin{abstract}
In Europe, the perforator method (EN 120) is the mostly used laboratory method of the wood-based panel industry. Usually, the measured perforator value depends on the moisture content of the boards. According to DIBt-100, the measured perforator values are corrected to a common moisture content (MC) of $6.5 \%$ using an established equation proposed by Jann and Deppe (1990). The correction factor of Jann and Deppe (1990) is based on the assumption that particle- and fibreboards change their perforator values to the same extent regardless whether increasing or decreasing the moisture content in the range of $3 \leq u \leq 9 \%$. Application of this correction factor to particle- and fibreboards of higher moisture content than $6.5 \%$ can lead to biased corrected results in favour of low emission. The corrected values can also lead to paradoxical relation between the perforator values and emission in the low-emission region.
\end{abstract}

\section{Introduction}

Aminoplastic resins, especially UF-resins, are the main binders used in the industry of wood-based panels. UF-resins are fast curing resins and of uncontested good performance. However, boards bonded with UF-resins are, in general, of limited

This article is dedicated to Gerd Wegener on the occasion of his retirement as professor at the Technische Universität München.

E. Roffael (ه)

Georg-August-Universität Göttingen, Büsgenweg 1, 37077 Göttingen, Germany

e-mail: eroffae1@gwdg.de

B. Johnsson

Casco Adhesives AB, P O Box 13000, SE-85013 Sundsvall, Sweden

B. Engström

Casco Adhesives AB, P O Box 11538, SE-10061 Stockholm, Sweden 
moisture resistance and emit also detectable amounts of formaldehyde. The amount of formaldehyde liberated from UF-bonded boards depends on a number of endogenic factors related to the resin and the production conditions of the boards. Moreover, exogenic factors, such as the relative humidity and temperature, under which the boards are tested (Peterson et al. 1972, 1973, 1974; Sundin et al. 1992) impact on the formaldehyde release. Additionally, ageing of the boards decreases their formaldehyde release significantly (Sundin and Roffael 1989). Therefore, the assessment of formaldehyde emanation is an intricate issue, to which over the last decades an untold number of publications pertains.

The literature describes many methods for measuring the liberation of formaldehyde from wood-based panels (Roffael 1993) in the laboratory. Recently, continuous methods have been also proposed for assessing the formaldehyde release during production in the factories (Engström 2007, 2008).

In Europe, mainly three laboratory methods for the determination of formaldehyde release have been standardised which are as follows:

1. Extraction method called the perforator method (EN 120)

2. Formaldehyde emission by the Gas analysis method (EN 717-2)

3. Formaldehyde emission by the flask method (EN 717-3)

Besides these methods, the formaldehyde emission of the boards can be measured using the chamber technique (EN 717-1), which is considered to be the reference method.

Among the above-mentioned laboratory methods, the perforator technique gained wide acceptance for assessing the emanation of formaldehyde from wood-based panels; the method can be used for both quality control of the boards in the factory as well as classification of the boards according to the guideline (DIBt-100 1994).

\section{The perforator method (EN 120)}

The perforator test is used primarily on specimens of raw or unfinished particleboards (PB), medium density fibreboards (MDF) and oriented strand boards (OSB). It involves boiling test specimens in toluene at nearly $110^{\circ} \mathrm{C}$. The extracted formaldehyde is collected in water and analysed photometrically. Within the range above 3 to $9 \%(3 \leq u \leq 9 \%)$ moisture content (MC), the measured perforator values are corrected to a common $\mathrm{MC}(6.5 \%)$ using an established equation proposed by Jann and Deppe (1990):

$$
F=-0.133 \times u+1.86
$$

( $F$ perforator correction factor, $u$ moisture content [\%])

The correction factor of Jann and Deppe (1990) is based on the assumption that particle and fibreboards change their perforator values to the same extent regardless whether increasing or decreasing the moisture content in the range of $3 \leq u \leq 9 \%$. The limit perforator values in Germany for particleboards, MDF and OSB are given in Table 1 according to the German regulations (DIBt-Richtlinie 100). 
Table 1 Limit perforator values for boards of the E1-class category

\section{Chamber}

value (vol. ppm)

0.1
Corresponding perforator value $(\mathrm{mg} / 100 \mathrm{~g})$

PB: 6.5 (8.0)

MDF: $7.0(8.0)$

OSB: $6.5(8.0)$

\section{State of knowledge}

In the literature, untold number of publications pertains to the perforator method and its field of application. Mayer (1978) established a curvilinear relationship between the formaldehyde content of the resins as expressed by the molar ratio F:U and the measured perforator value (Fig. 1). As can be seen from Fig. 1, a more or less linear relation exists between the perforator value and the molar ratio of the resin in the range between $\mathrm{U}: \mathrm{F} 1: 1.4$ and $\mathrm{U}: \mathrm{F}$ 1:1.8. In the range below $\mathrm{U}: \mathrm{F}$ 1:1.1, decreasing the formaldehyde content in the resins leads to disproportionally little change in the perforator value of the boards. This indicates that the perforator value in this low region of emission is by far less sensitive to changes in the formaldehyde content of the boards than in the high molar ratio region. This is a serious drawback, since nowadays a substantial amount of particle- and fibreboards are bonded with lowfuming UF-resins with molar ratio U:F of 1:1 or even higher.

\section{Results and discussion}

Measurement of the change in the perforator value of aged particle- and fibreboards after climatisation at different relative humidities (30, 65 and $85 \%)$ leads to the

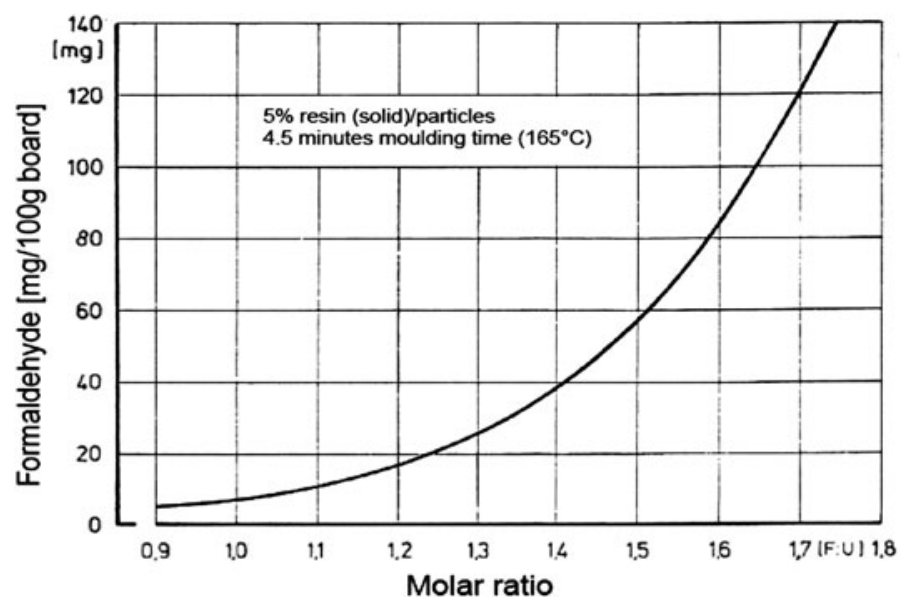

Fig. 1 Change in the formaldehyde release (FESYP-perforator method) with the molar ratio of UF-resins (Mayer 1978) 
following results: Increasing relative humidity during storage drives the moisture content of the boards to higher values and increases the measured perforator values as well. However, the corrected perforator values decline in the same direction. This phenomenon was observed in case of particleboards of different thickness (Fig. 2) as well as in case of medium density fibreboards (Fig. 3). In both cases, the correction factor seems to go beyond the mere compensation of the moisture influence on the perforator value. This becomes also evident from Fig. 4 showing that the emission level in the $1 \mathrm{~m}^{3}$ chamber of the boards after preclimatisation to different moisture contents. As can be concluded from the results, boards climatisated to higher moisture content emit also under equilibrium conditions higher amounts of formaldehyde in the chamber, this irrespective of the thickness of the boards. The difference in the emission level may reach about $0.03 \mathrm{ppm}$.

Further systematic investigations into the influence of moisture content of three fibreboards on the perforator value showed that the relation between moisture content and perforator values can be represented by a straight line (Fig. 5). However, the slope of the straight line representing the linear relation between moisture content and the perforator value is different for the various fibreboards

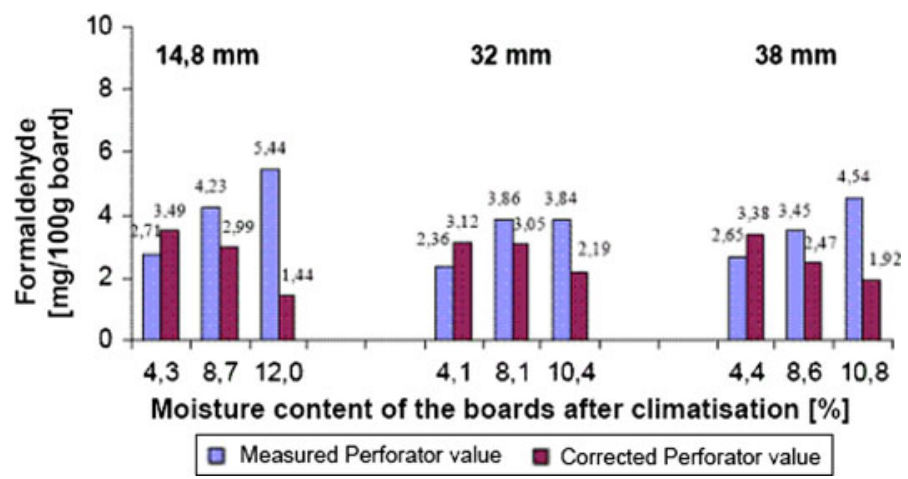

Fig. 2 Change in the measured and corrected perforator value of UF-bonded particleboards with increasing moisture content (Witkavel 2004)

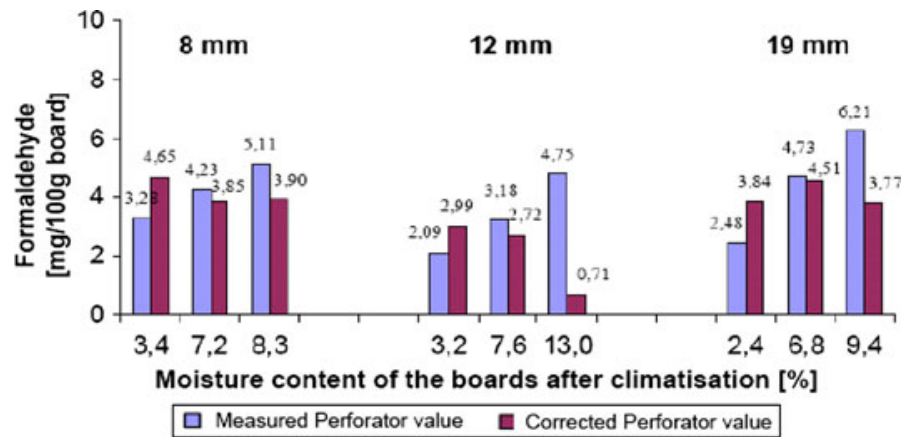

Fig. 3 Change in the measured and corrected perforator value of UF-bonded fibreboards with increasing moisture content (Witkavel 2004) 


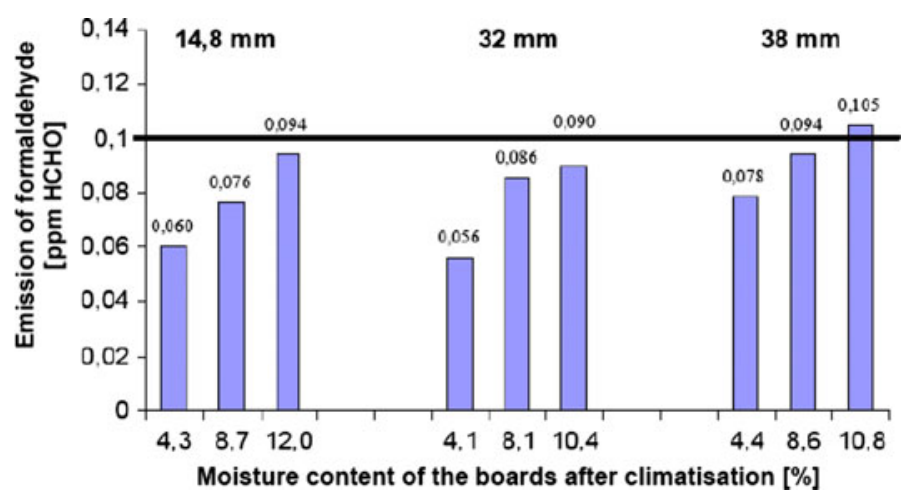

Fig. 4 Formaldehyde emission (EN 717-1) of particleboards in the $1 \mathrm{~m}^{3}$ chamber (Witkavel 2004)

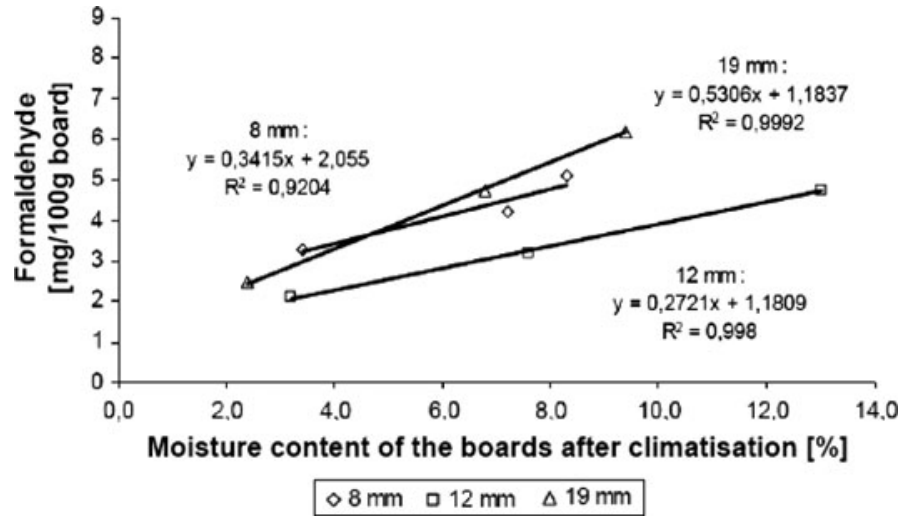

Fig. 5 Correlation between moisture content and measured perforator value of UF-bonded fibreboards (Witkavel 2004)

investigated. The $12 \mathrm{~mm}$ fibreboard showed a slope of 0.27 and the $19 \mathrm{~mm}$ board a slope of 0.53 . This is a strong indicator that the change of the measured perforator value with the moisture content is not the same for all aminoplastic-bonded boards, as originally assumed by the empirical formula published by Jann and Deppe (1990). This conclusion is in line with previous results published by Roffael and Mehlhorn (1980), who found that the molar ratio is an important factor as far as the relation between the perforator value and the moisture content is concerned, as shown in Figs. 6 and 7. All the above cited results unambiguously point out that the correction factor suffers from the deficiency of not including all factors affecting the change of the perforator value with the moisture content. The relation between the perforator content and the moisture content is multifactorial and not as simple as the correction formula implies.

Modification of UF-resins with melamine or melamine resins increases their moisture resistance. Consequently, the change in the measured perforator value of the boards bonded with modified resins as a function of moisture content is less concise than in the case of unmodified resins, as it becomes evident from Fig. 8. 


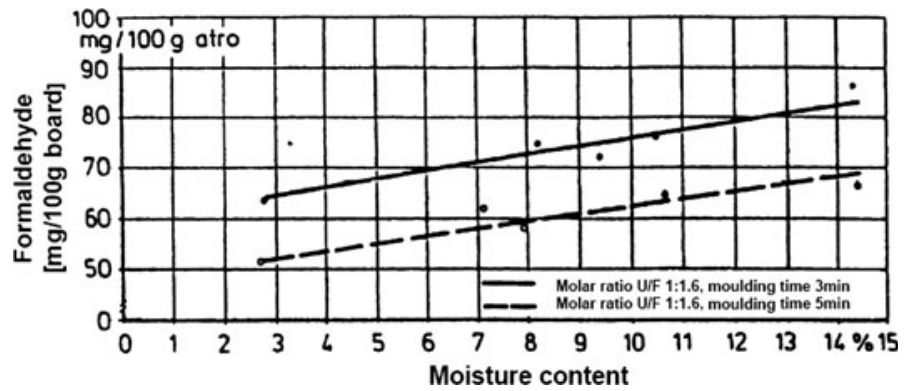

Fig. 6 Influence of moisture content of approximately 1-year-old UF-bonded particleboards on their measured perforator value; the boards were bonded with an UF-resin with a molar ratio U:F of 1:1.6 (Roffael and Mehlhorn 1980)

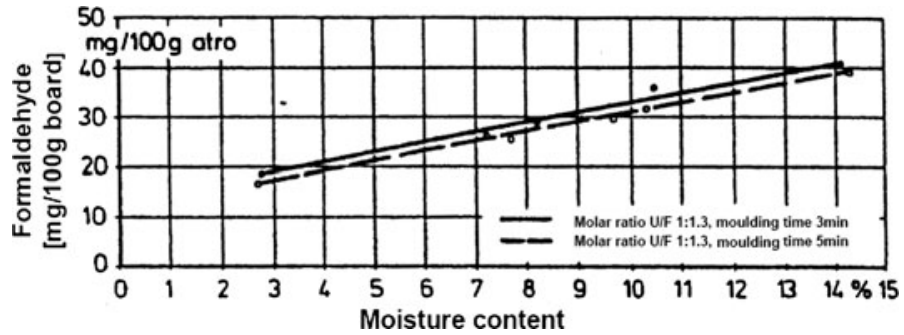

Fig. 7 Influence of moisture content of approximately 1-year-old UF-bonded particleboards on their measured perforator value; the boards were bonded with an UF-resin with a molar ratio U:F of 1:1.3 (Roffael and Mehlhorn 1980)

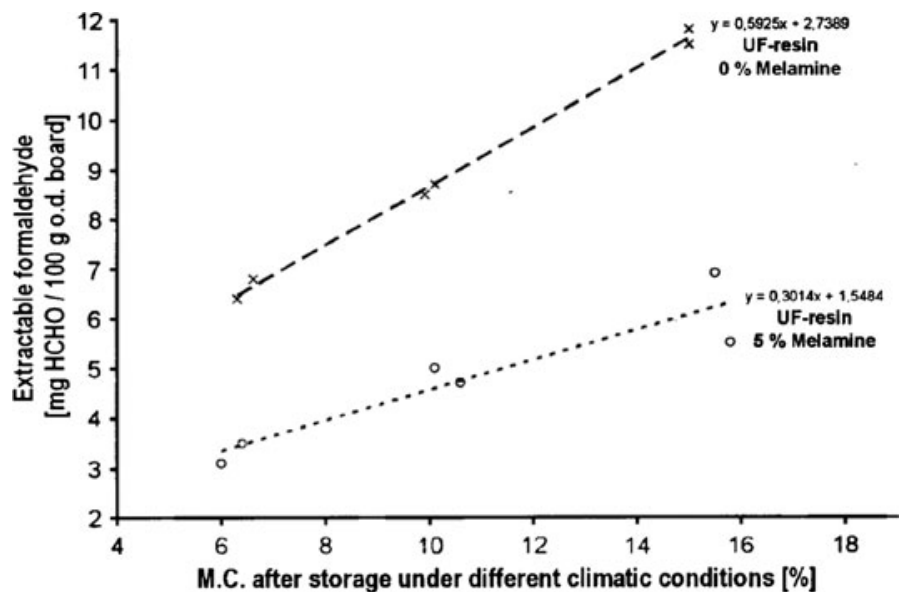

Fig. 8 Correlation between the perforator value and the moisture content of UF- and MUF-bonded particleboards (Roffael et al. 2001) 


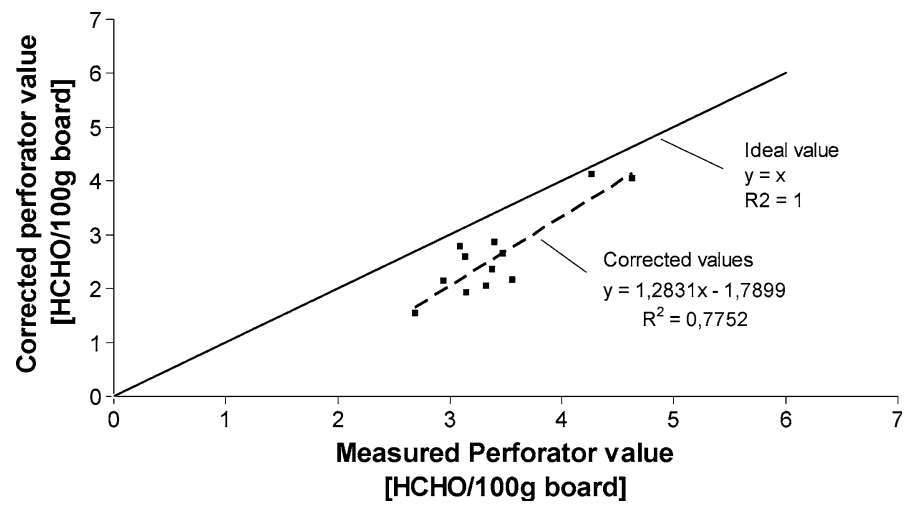

Fig. 9 Correction factor according to Jann and Deppe (1990) against the ideal line (Roffael and Witkavel 2002)

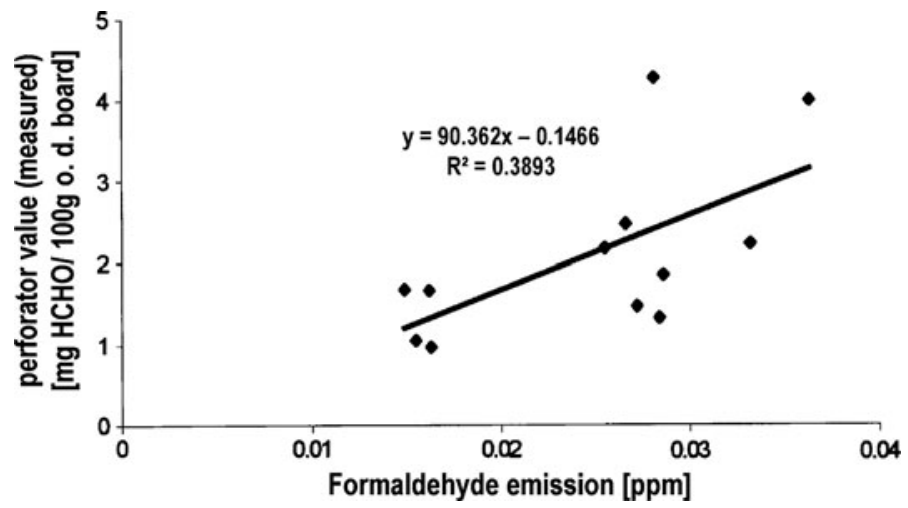

Fig. 10 Correlation between the measured perforator value and formaldehyde emission in the $1 \mathrm{~m}^{3}$ chamber (Roffael 2004)

Figure 9 shows a hypothetical ideal case, where the moisture content has no influence on the measured perforator value. In this case, the measured and corrected perforator values would be the same, in other words, the correction factor is 1 . Therefore, if any measured perforator value is to be ideally corrected to eliminate the influence of moisture content, the corrected value will be on the ideal line or on a parallel line, where no influence of the moisture content on the perforator value exists. However, as can be seen from Fig. 9, the corrected perforator values using the formula of Jann and Deppe (1990) deviate strongly from the ideal line. The deviation from the ideal case seems to be more pronounced at low perforator value levels.

Undisputed hard evidence of the shortcoming of the correction factor can be derived from Figs. 10 and 11, where the measured and corrected perforator values of low-emission boards are plotted against the emission of the boards in the $1 \mathrm{~m}^{3}$ chamber. The measured uncorrected perforator values show a loose correlation with 


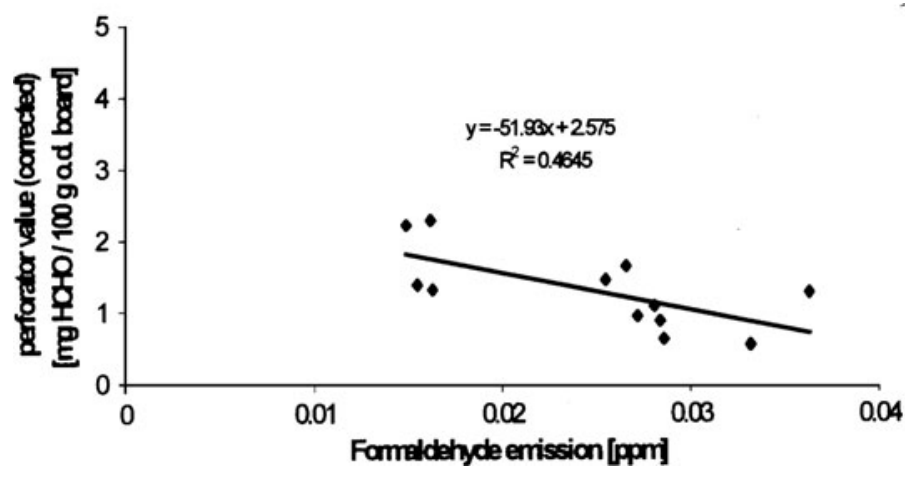

Fig. 11 Correlation between the corrected perforator value and the formaldehyde emission in the $1 \mathrm{~m}^{3}$ chamber (Roffael 2004)

the emission in the chamber. Nevertheless, the emission rises with increasing perforator value (Fig. 10). The corrected perforator values, however, correlate inversely with the emission showing a decrease in the emission with increase in the perforator value (Fig. 11).

\section{Conclusion}

Summing up the whole results, it becomes clear that the corrected perforator value of the same board decreases with increasing moisture content over 6.5\%. Moreover, the change in the measured perforator value with the moisture distinctly is different for boards bonded with different binders. In the very low region of emission, the corrected perforator value could lead to an inverse relation between the perforator value and the emission in the chamber as the correction factor goes beyond counter balancing the moisture effect. As this result is paradoxical, there is enough reason to revise the use of the perforator method for detecting small differences in the emission of boards in the low-emission range.

Open Access This article is distributed under the terms of the Creative Commons Attribution Noncommercial License which permits any noncommercial use, distribution, and reproduction in any medium, provided the original author(s) and source are credited.

\section{References}

DIBt-Richtlinie 100 Deutsches Institut für Bautechnik (1994) Richtlinie über die Klassifizierung und Überwachung von Holzwerkstoffplatten bezüglich der Formaldehydabgabe, Fassung Juli 1994

Engström B (2007) Online measurement of formaldehyde in the wood-based industry. Vortrag gehalten anlässlich der 2. Tagung ,holztechnologie” am 06. 11. 2007 in Fellbach/Stuttgart

Engström B (2008) Evaluation of Formaldehyde release from low-Emission composite board. Vortrag gehalten anlässlich der 3. Tagung „holztechnologie” am 27. 11. 2008 in Göttingen

Jann O, Deppe HJ (1990) Zur Berücksichtigung der Materialfeuchte bei der Formaldehydmessung von Spanplatten. Holz Roh- Werkst 48:365-368 
Mayer J (1978) Chemische Aspekte bei der Entwicklung formaldehydarmer Klebstoffe für die Holzwerkstoffindustrie. In: Spanplatten-Heute und Morgen, DRW-Verlag, Stuttgart, pp 102-111

Peterson H, Reuther W, Eisele W, Wittmann O (1972) Zur Formaldehydabspaltung bei der Spanplattenerzeugung mit Harnstoff-Formaldehyd-Bindemitteln; 1. Mitteilung. Holz Roh- Werkst 30, pp 429-436

Peterson H, Reuther W, Eisele W, Wittmann O (1973) Zur Formaldehydabspaltung bei der Spanplattenerzeugung mit Harnstoff-Formaldehyd-Bindemitteln; 2. Mitteilung: der Einfluss der Festharzmenge, Preßzeit, und Preßtemperatur. Holz Roh- Werkst 31:463-469

Peterson H, Reuther W, Eisele W, Wittmann O (1974) Zur Formaldehydabspaltung bei der Spanplattenerzeugung mit Harnstoff-Formaldehyd-Bindemitteln; 3. Mitteilung: der Einfluss von Härterart, Härtermenge und formaldehydbindenen Mitteln. Holz Roh- Werkst 32:402-410

Roffael E (1993) Formaldehyde release from particleboard and other wood based panels. Malayan forest records no. 37

Roffael E (2004) Unpublished results

Roffael E, Mehlhorn L (1980) Einfluß der Randbedingungen bei der Bestimmung des extrahierbaren Formaldehyds in Holzspanplatten nach der Perforatormethode. Holz Roh- Werkst 38:85-88

Roffael E, Witkavel A (2002) Erhöhung der Korrelationssicherheit zwischen dem Feuchtigkeitsgehalt von Holzspan- und mitteldichten Faserplatten (MDF) und ihrem Formaldehydgehalt ermittelt nach dem Perforatorverfahren (EN 120). Schlussbericht zum AiF-Projekt 12720 (s. auch Witkavel 2004)

Roffael E, Dix B, Schneider T, Colakoglu G (2001) Influence of moisture content on the formaldehyde release of particle- and medium density fibreboards (MDF) bonded with formaldehyde based adhesives. In: Proceedings of 5th European panel products symposium 2001, pp 144-154

Sundin B, Roffael E (1989) Einfluß der Alterung auf die Formaldehydemissionen von UF-Spanplatten niedrigen Formaldehydabgabepotentials. Holz-Zent.bl. 115:704

Sundin B, Risholm-Sundman M, Edenholh K (1992) Emission of formaldehyde and other volatile organic compounds (VOC) from sawdust and lumber, different wood-based panels and other building materials: a comparative study. Vortrag gehalten anlässlich des 26. International particleboard/ composite materials symposium, Washington State University, Pullman, USA am 7.-9.4.1992

Witkavel A (2004) Beiträge zur Beurteilung der Formaldehydabgabe von Holzspan- und mitteldichten Faserplatten (MDF) im niedrigen Formaldehydabgabebereich. Dissertation, Georg-August-Universität Göttingen 